\title{
Inicio del brote de Influenza A (H1N1) pandémica en Chile: caracterización genética de los primeros casos detectados
}

\author{
RODRIGO A. FASCE ${ }^{1}$, JAVIER TOGNARELLI ${ }^{2}$, JUDITH MORA ${ }^{3}$, \\ GRACIELA TORRES ${ }^{1}$, WINSTON ANDRADE ${ }^{1}$, PATRICIA BUSTOS ${ }^{1}$, \\ PAMELA ARAYA ${ }^{2}$, MONSERRAT BALANDA ${ }^{4}$, CAROLINA AGUAYO ${ }^{2}$, \\ JORGE SEIN ${ }^{5}$, EUGENIO RAMÍREZ ${ }^{4}$, JORGE FERNÁNDEZ ${ }^{2}$
}

\section{Genetic characterization of the virus causing H1N1 influenza pandemic in Chile. Analysis of the first detected cases}

Background: Following the announcement of the Influenza A(H1N1) pandemic by the World Health Organization in April 2009, a surveillance program was carried out in Chile to detect the introduction of the virus in the country and to monitor its propagation and impact. Aim: To describe the onset of the outbreak and the genetic characterization of the pandemic H1N1 influenza virus in the first detected cases in Chile. Material and Methods: Analysis of 18 clinical samples coming from suspicious patients, received in a National Reference Laboratory. RNA reverse transcription and real time influenza gene DNA amplification was carried out in a 7500 Fast and Step One Real Time PCR Systems of Applied Biosystems and MxPro-Mx3000P thermocycler from Stratagene. Super Script III Platinum One-Step Quantitative RT-PCR was used. Results: The virus was first detected in three persons returning from the Dominican Republic via Panama and a child from the east zone of Santiago. Genetic characterization of the virus showed that the child was infected by a different variant of the pandemic virus than the three persons returning from the Caribbean. Conclusions: The onset of the Influenza outbreak in Chile apparently came from two different epidemiological groups. The spread of the virus detected in the voyagers was limited immediately. However the virus of the fourth case was found in different regions of Chile.

(Rev Med Chile 2011; 139: 833-840).

Key words: Influenza A virus, H1N1 subtype; Pandemics.

'Sección Virus Respiratorios
y Exantemáticos.
${ }^{2}$ Subdepartamentos de
Genética Molecular.
${ }^{3}$ Enfermedades Virales.
${ }^{4}$ Secciones de Virus
Oncogénicos.
5SIDA.
Instituto de Salud Pública
(ISP), Chile.
Recibido el 21 de
septiembre de 2010,
aceptado el 9 de mayo de
2011.
Correspondencia a:
Jorge Fernández O.
Subdepartamento Genética
Molecular, Instituto de
Salud Pública de Chile,
Av. Marathon 1000,
Santiago, Chile.
E-mail: jfernand@ispch.cl

1 l virus Influenza A (H1N1), inicialmente llamada influenza porcina, se originó a través de una recombinación triple de virus de origen humano, aviar y porcino. Su circulación se detectó inicialmente en cerdos y en algunos casos humanos en Estados Unidos de Norteamérica en 1998 y $2005^{1,2}$.

Los primeros casos se detectaron en México en marzo de 2009, el 21 de Abril el CDC de Atlanta confirmó la presencia de un nuevo virus en dos niños del sur de California ${ }^{3,4}$. Desde el comienzo de su detección y hasta junio de 2009, en México se reportaron 5.029 casos de pacientes infectados y 97 personas fallecidas por este virus ${ }^{3,5}$. En sus inicios esta epidemia se propagó rápidamente, alcanzando en 10 días a Estados Unidos de Norteamérica, en 15 días a América y en 74 días a un número importante de países del mundo. El 16 de junio de 2009 la OMS declaró la fase 6, es decir, fase pandémica con brotes a nivel comunitario en al menos 2 países en distintas regiones del mundo ${ }^{6}$. El 27 de diciembre de 2009 el virus pandémico 
H1N1 se había expandido a más de 208 países provocando alrededor de 12.220 muertes $^{7}$.

El 24 de abril de 2009 el Ministerio de Salud emitió una alerta nacional con el fin de reforzar la vigilancia de influenza y de virus respiratorios en el país, solicitando el envío al Instituto de Salud Pública de la totalidad de los virus de influenza detectados por la red de vigilancia de laboratorios en los servicios públicos del país, como también a los laboratorios privados.

En Chile, el inicio del brote pandémico coincidió con el inicio de la temporada de invierno, con una co-circulación de la gripe estacional y pandémica.

Los primeros casos de influenza pandémica H1N1 fueron confirmados el 16 de mayo de 2009 en la Región Metropolitana de Santiago. Posteriormente, se produjo un fuerte aumento en los casos a lo largo de todo el país, posicionando a nuestro país en el sexto lugar en el mundo y primero en América del Sur, con un total de 12.297 casos confirmados y 152 muertes al 30 de diciembre de $2009^{8}$.

El objetivo de este trabajo es describir el inicio del brote y la caracterización genética del virus influenza $\mathrm{H} 1 \mathrm{~N} 1$ pandémico en los primeros casos detectados en Chile.

\section{Materiales y Métodos}

\section{Muestras clínicas}

En este estudio se incluyen un total de 18 muestras clínicas provenientes de pacientes sospechosos de estar infectados con virus pandémico H1N1, que fueron recibidas en el Laboratorio de Referencia Nacional, Sección Virus Respiratorios y Exantemáticos del Instituto de Salud Pública de Chile, para su confirmación en mayo de 2009. Tres casos sospechosos provenientes de Punta Cana, República Dominicana y Panamá, fueron detectados por las barreras de contención impuestas por el Ministerio de Salud en el Aeropuerto Arturo Merino Benítez. Otro caso sospechoso fue detectado en Integramédica, sin historial de viaje, y 3 contactos de este último caso. También se analizaron 11 casos sospechosos correspondientes a diferentes ciudades del país (Tabla 1). Los casos sospechosos de estar infectados por influenza pandémica $\mathrm{H} 1 \mathrm{~N} 1$ tuvieron en general un diagnóstico de fiebre sobre $\operatorname{los} 38^{\circ} \mathrm{C}$, mialgia, dolor de garganta, tos, rinorrea.
La edad de los pacientes estudiados fue de entre 6 y 47 años, 12 eran de sexo masculino y 6 de sexo femenino. Tabla 1.

\section{Extracción de ácidos nucleicos}

La extracción de ácidos nucleicos totales fue realizada en un extractor automatizado, Nuclisens easyMAG, Biomérieux usando 0,6 mL de la muestra respiratoria colectada; tanto aspirado nasofaríngeo (ANF) o tórula nasofaringea. La carga de las muestras en el buffer de lisis fue realizado en el laboratorio BSL39.

\section{Transcripción reversa y amplificación de ADN}

La transcripción reversa de ARN y amplificación de $\mathrm{ADN}$ en tiempo real de los genes en influenza fue realizado en 7500 Fast y Step One Real Time PCR Systems de Applied Biosystems y el termociclador MxPro-Mx3000P de Stratagene. Se utilizó el sistema Super Script III Platinum One-Step Quantitative RT-PCR de Invitrogen. Los partidores, sondas para la Influenza humana A (gen M; InfA), nucleoproteína Porcina Universal (gen NP; SwA), Hemaglutinina Porcina ( $\mathrm{SwH} 1$ ), RNP humana y el virus de Influenza control positivo (tipo porcino) fueron obtenidos del panel de detección RT-PCR en tiempo real de la influenza porcina del CDC (FLUSW01). Para la tipificación de las muestras de Influenza estacional se usó RT-PCR en tiempo real del virus de la Influenza Humana y el panel de caracterización desde CDC (Catálogo KT 0078) que contenía partidores y sondas para las cepas H1 y H3 de influenza estacional. Los parámetros de los ciclos y la interpretación de los resultados se ajustaron al protocolo RT-PCR en tiempo real para la detección y caracterización de la influenza porcina del CDC, versión 2009 (Ref \# I-007-05) ${ }^{10}$.

\section{Amplificación y secuenciación}

Para caracterizar genéticamente el virus $\mathrm{H} 1 \mathrm{~N} 1$ pandémico se amplificó una región de 1.200 pares de bases del gen que codifica para la Hemaglutinina, utilizando partidores descritos por el CDC de Atlanta $^{11}$. La transcripción reversa fue realizada a $50^{\circ} \mathrm{C}$ por $30 \mathrm{~min}$, posteriormente se realizó una amplificación de 35 ciclos que consistió en: $95^{\circ} \mathrm{C}$ por $1 \mathrm{~min}$, hibridación a $55^{\circ} \mathrm{C}$ por $1 \mathrm{~min}$ y $72^{\circ} \mathrm{C}$ por $1 \mathrm{~min}$, con una extensión final a $72^{\circ} \mathrm{C}$ por 5 min. La amplificación se realizó utilizando un termociclador modelo 2700 (Applied Biosystems, ciudad Fosted, CA). 
Tabla 1. Características clínicas, epidemiológicas y demográficas de 18 pacientes infectados con el virus de la Influenza A (H1N1) pandémica del año 2009

\begin{tabular}{|c|c|c|c|c|c|c|}
\hline Casos & $\begin{array}{l}\text { Edad } \\
\text { (años) }\end{array}$ & Sexo & $\begin{array}{l}\text { Cuidad de } \\
\text { origen }\end{array}$ & $\begin{array}{l}\text { Fecha de } \\
\text { obtención de } \\
\text { la muestra }\end{array}$ & $\begin{array}{l}\text { Evolución } \\
\text { (días) }\end{array}$ & Síntomas \\
\hline Caso 1 & 32 & $\mathrm{~F}$ & $\begin{array}{l}\text { Retorno desde } \\
\text { República Domi- } \\
\text { nicana }\end{array}$ & May 16 & 3 & $\begin{array}{l}\text { Fiebre sobre } 38^{\circ} \mathrm{C}, \mathrm{CEG} \text {, mialgia, } \\
\text { rinitis, rinorrea, otalgia, dolor de } \\
\text { garganta, tos }\end{array}$ \\
\hline Caso 2 & 25 & $\mathrm{~F}$ & $\begin{array}{l}\text { Retorno desde } \\
\text { República Domi- } \\
\text { nicana }\end{array}$ & May 16 & 1 & $\begin{array}{l}\text { Fiebre sobre } 38^{\circ} \mathrm{C}, \mathrm{CEG} \text {, mialgia, } \\
\text { otalgia, dolor de garganta, tos }\end{array}$ \\
\hline Caso 3 & 24 & M & $\begin{array}{l}\text { Retorno desde } \\
\text { Panamá }\end{array}$ & May 20 & 1 & $\begin{array}{l}\text { Fiebre, dolor de cabeza, mialgia, } \\
\text { dolor de garganta, dificultad res- } \\
\text { piratoria }\end{array}$ \\
\hline Caso 4 & 6 & M & Santiago & May 14 & 3 & Fiebre, dolor de cabeza, rinorrea \\
\hline Caso 5 & 6 & M & Santiago & May 17 & 6 & Fiebre, dolor de cabeza, rinorrea \\
\hline Caso 6 & 6 & M & Santiago & May 18 & 2 & $\begin{array}{l}\text { Fiebre sobre } 38^{\circ} \mathrm{C} \text {, dolor de ca- } \\
\text { beza, tos }\end{array}$ \\
\hline Caso 7 & 11 & M & Santiago & May 18 & 0,5 & $\begin{array}{l}\text { Fiebre sobre } 38^{\circ} \mathrm{C} \text {, dolor de gar- } \\
\text { ganta, tos }\end{array}$ \\
\hline Caso 8 & 47 & $\mathrm{~F}$ & Santiago & May 18 & 3 & $\begin{array}{l}\text { Fiebre sobre } 38^{\circ} \mathrm{C} \text {, dolor de gar- } \\
\text { ganta, tos }\end{array}$ \\
\hline Caso 9 & 22 & M & Santiago & May 21 & 4 & $\begin{array}{l}\text { Fiebre sobre } 38^{\circ} \mathrm{C} \text {, dolor de gar- } \\
\text { ganta, tos }\end{array}$ \\
\hline Caso 10 & 19 & M & Santiago & May 22 & 3 & $\begin{array}{l}\text { Fiebre sobre } 38^{\circ} \mathrm{C} \text {, mialgia, dolor } \\
\text { de garganta, tos }\end{array}$ \\
\hline Caso 11 & 10 & $\mathrm{M}$ & Rancagua & May 22 & 1 & $\begin{array}{l}\text { Fiebre sobre } 38^{\circ} \mathrm{C} \text {, dolor de gar- } \\
\text { ganta, dolor de cabeza, tos }\end{array}$ \\
\hline Caso12 & 14 & $\mathrm{~F}$ & Puerto Montt & May 19 & 2 & $\begin{array}{l}\text { Fiebre sobre } 38^{\circ} \mathrm{C} \text {, dolor de gar- } \\
\text { ganta, rinorroea, tos }\end{array}$ \\
\hline Caso 13 & 30 & M & Puerto Montt & May 25 & 7 & $\begin{array}{l}\text { Neumonía bilateral, falla respira- } \\
\text { toria, caso severo, UCI. Fallecido el } \\
18 \text { de Junio }\end{array}$ \\
\hline Caso 14 & 11 & M & Concepción & May 26 & 2 & $\begin{array}{l}\text { Fiebre sobre } 38^{\circ} \mathrm{C} \text {, mialgia, dolor } \\
\text { de garganta, tos, rinorrea }\end{array}$ \\
\hline Caso 15 & 30 & M & Puerto Montt & May 26 & 13 & $\begin{array}{l}\text { Fiebre sobre } 38^{\circ} \mathrm{C} \text {, mialgia, dolor } \\
\text { de garganta, tos. Neumonía se- } \\
\text { vera, UCI. Fallecido el } 17 \text { de junio }\end{array}$ \\
\hline Caso 16 & 17 & $\mathrm{~F}$ & Arica & May 27 & 0 & $\begin{array}{l}\text { Fiebre sobre } 38^{\circ} \text { C, tos seca, } \\
\text { rinorroea, mialgia, contacto con } \\
\text { personas infectadas el } 23 \text { de mayo }\end{array}$ \\
\hline Caso 17 & 11 & M & Hualpen, Biobío & May 27 & 2 & $\begin{array}{l}\text { Fiebre sobre } 38^{\circ} \mathrm{C} \text {, tos seca, rino- } \\
\text { rroea, dolor de garganta, vómitos, } \\
\text { otalgia bilateral, hinchazón de } \\
\text { lengua }\end{array}$ \\
\hline Caso 18 & 21 & $\mathrm{~F}$ & Viña del Mar & May 28 & 4 & $\begin{array}{l}\text { Dolor de cabeza, tos, mialgia, } \\
\text { rinorrea }\end{array}$ \\
\hline
\end{tabular}


La secuenciación fue realizada con terminadores dideoxinucleotidos fluorescentes por el uso de ABI PRISM big Dye terminator cycle sequencing ready reaction kit (Applied Biosystems, Foster City, Calif). Las secuencias nucleotídicas fueron analizados por un analizador genético ABI PRISM 310 (Applied Biosystems). Los datos de secuencia generados fueron ensamblados y editados electrónicamente con los programas ALIGN, EDITSEQ y MEGALING (DNASTAR, Madison) ${ }^{12}$.

\section{Resultados}

Una vez que comenzó a propagarse el virus pandémico H1N1 desde México y Estados Unidos de Norteamérica a otros países, el Ministerio de Salud envió una circular a los laboratorios del país con el fin reforzar la pesquisa de casos e implementó una barrera de control de temperatura en el Aeropuerto Arturo Merino Benítez. La vigilancia permitió detectar los 2 primeros casos (caso 1 y caso 2) importados de influenza pandémica $\mathrm{H} 1 \mathrm{~N} 1$ en el Aeropuerto de Santiago en un vuelo proveniente desde Punta Cana, República Dominicana. Los dos casos correspondían a personas de sexo femenino de 32 y 25 años con síntomas como fiebre sobre $38^{\circ} \mathrm{C}$, mialgia, otalgia, dolor de garganta, tos (Tabla 1). Una vez detectado el estado febril, ambas pacientes fueron trasladadas desde el aeropuerto a recintos asistenciales (Hospital del Tórax y Clínica Dávila) donde fueron aisladas y sometidas a protocolos de control de la influenza. En ambos centros asistenciales se tomó a las pacientes una muestra de aspirado nasofaríngeo, las cuales fueron enviadas al Laboratorio de Referencia para su confirmación. El día 16 de mayo el Instituto de Salud Pública informó que el análisis mediante RT-PCR en tiempo real fue positivo para InfA, $S w A$ y $S w H 1$ y negativo para virus influenza estacional $\mathrm{H} 1$ y $\mathrm{H} 3$. El caso 3 correspondió a un hombre de 24 años proveniente de Panamá que viajó en el mismo avión junto a los casos 1 y 2 descritos anteriormente, y que comenzó con síntomas posteriormente.

El día 11 de mayo de 2009 un niño de 6 años (caso 4) residente en Santiago, comenzó con síntomas asociados a una infección por influenza: fiebre, dolor de cabeza y rinorrea, siendo atendido en Integramédica. El día 14 de mayo se diagnóstico Influenza A por Inmunofluorescencia en el centro asistencial y el día de 16 de Mayo el caso fue confir- mado por RT-PCR en tiempo real para $\operatorname{InfA} S w A$, $S w H 1$. Este paciente no había viajado al extranjero durante el año 2009 y ni él ni su familia tuvieron contacto con personas que hubiesen viajado al extranjero en los últimos 3 meses. Posteriormente, 3 contactos con los mismos síntomas del caso 4 (caso 5, caso 6 y caso 7) y que provenían del mismo colegio de la zona oriente de Santiago fueron confirmados en el ISP como positivos a Influenza H1N1 pandémica.

En este trabajo también se analizaron muestras de pacientes (casos 8-18) que fueron tomadas entre los días 19 y 28 de mayo de la zona norte, centro y sur del país (Tabla 1). Ninguno de estos pacientes tenía antecedentes de haber viajado al extranjero y tampoco de haber tenido contacto con alguna persona que hubiese estado fuera del país.

Para determinar si el virus influenza pandémico H1N1 detectado en Chile era similar a los que se encontraron en México y Estados Unidos de Norteamérica se analizó una región de 1.200 pares de bases del gen $H A$ que codifica la hemaglutinina, proteína de la cubierta del virus. El análisis genético realizado al virus influenza detectado en los casos 1, 2 y 3 provenientes de República Dominicana y Panamá demostró una identidad nucleotídica de $99,5 \%$ con respecto a la cepa de referencia A/California/14/2009. Cuando se comparó la secuencia de aminoácido de estos virus influenza se encontró una identidad de 99,4\%, identificándose 2 cambios de aminoácidos L49I y T220S con respecto a la cepa de referencia (Tabla 2). Ninguna de las substituciones de aminoácidos encontradas afectó al sitio de unión del receptor.

Cuando se comparó la secuencia nucleotídica de los virus influenza de los casos 4, 5, 6 y 7 éstos tenían $100 \%$ de identidad con la cepa de referencia A/California/14/2009 (Tabla 2). En ninguna de las secuencias obtenidas de estos casos se detectaron las mutaciones L49I y T220S encontradas en los tres primeros casos. En ningún momento hubo contacto entre ambos grupos de pacientes.

El análisis genético realizado a los virus influenza correspondiente a los casos 8-18 demostró entre 99,8 y $100 \%$ de identidad nucleotídica y entre 1 y $100 \%$ de identidad animoacídica con respecto a la cepa de referencia y al caso 4 (Tabla 2). Las sustituciones de aminoácidos en estas cepas de virus Influenza fueron diferentes a las encontradas en el grupo proveniente de República Dominicana y Panamá. 
Influenza A (H1N1) en Chile - R. A. Fasce et al

Tabla 2. Comparación de la secuencia aminoacídica del virus A/California/14/2009 y el virus de la Influenza A (H1N1) pandémica del año 2009 en 18 pacientes chilenos

\begin{tabular}{|lcccc|}
\hline Aislado clínico & $\begin{array}{c}\text { Producto } \\
\text { génico }\end{array}$ & $\begin{array}{c}\text { Homología de la secuencia } \\
\text { aminoacídica (\%) }\end{array}$ & $\begin{array}{c}\text { n de aminoácidos } \\
\text { diferentes }\end{array}$ & $\begin{array}{c}\text { Cambio de } \\
\text { aminoácido }\end{array}$ \\
\hline A/Chile/9113/2009 & HA & 99,4 & 2 & L491, T220S \\
\hline A/Chile/8873/2009 & HA & 99,4 & 2 & L491, T220S \\
\hline A/Chile/8876/2009 & HA & 99,4 & 2 & L49, T220S \\
\hline A/Chile/8949/2009 & HA & 100 & 0 & \\
\hline A/Chile/8957/2009 & HA & 100 & 0 & \\
\hline A/Chile/8886/2009 & HA & 100 & 0 & \\
\hline A/Chile/8883/2009 & HA & 100 & 0 & \\
\hline A/Chile/8742/2009 & HA & 100 & 0 & \\
\hline A/Chile/9590/2009 & HA & 100 & 0 & \\
\hline A/Chile/9607/2009 & HA & 100 & 0 & \\
\hline A/Chile/9674/2009 & HA & 100 & 0 & \\
\hline A/Chile/9721/2009 & HA & 100 & 0 & \\
\hline A/Chile/10084/2009 & HA & 100 & 0 & 207 \\
\hline A/Chile/10194/2009 & HA & 100 & 0 & \\
\hline A/Chile/10352/2009 & HA & 99,4 & 2 & \\
\hline A/Chile/10610/2009 & HA & 99,7 & 1 & \\
\hline A/Chile/10660/2009 & HA & 100 & 0 & 1 \\
\hline A/Chile/10663/2009 & HA & 99,7 & & \\
\hline & & & 295 & \\
\hline
\end{tabular}

El análisis filogenético de cepas chilenas del virus de Influenza H1N1 pandémico demostró que estas cepas se agruparon con Influenza H1N1 pandémico detectados en otras regiones del mundo (Figura 1). En cambio, los virus Influenza H1N1 estacionales segregaron en un grupo diferente.

\section{Discusión}

Los casos 1 y 2, detectados como sospechosos por las barreras de contención impuestas por las autoridades de salud en el aeropuerto Arturo Merino Benítez, fue la primera alerta que se tuvo de que el virus había llegado a nuestro país. El análisis genético del virus influenza detectado en estos dos casos y del caso 3 que también venía en el mismo avión demostró que el virus tenía 100\% de similitud. Estos resultados demuestran que esos tres casos fueron infectados desde la misma fuente ya que dos de ellos pasaron una semana juntos en
Punta Cana, República Dominicana, y el tercer caso tuvo contacto con ellos en el vuelo de retorno desde Panamá a Santiago. El análisis genético además demostró que las cepas de virus Influenza de estos 3 casos presentaron mutaciones idénticas en el gen que codifica para la Hemaglutinina de la cubierta de virus, en comparación con los casos 4, 5, 6 y 7 detectados en Santiago que no tenían estas mutaciones. Al comparar la secuencia del gen de la Hemaglutinina de los virus detectados en los 3 pacientes provenientes de República Dominicana vía Panamá con las disponibles en la base de secuencias del GenBank, se encontró que esta misma variante viral fue detectada en República Dominicana entre los días 23 al 26 de mayo de 2009 (número de acceso CY049915, CY0449907, CY043110, CY043102). El 22 de mayo de 2009 fue detectado en Rusia y en el mes de junio de 2009 fue detectada en Alaska y Francia (número de acceso CY069667, GQ329093 y GQ255897). Estos resultados nos permiten concluir que los casos $1 \mathrm{y}$ 


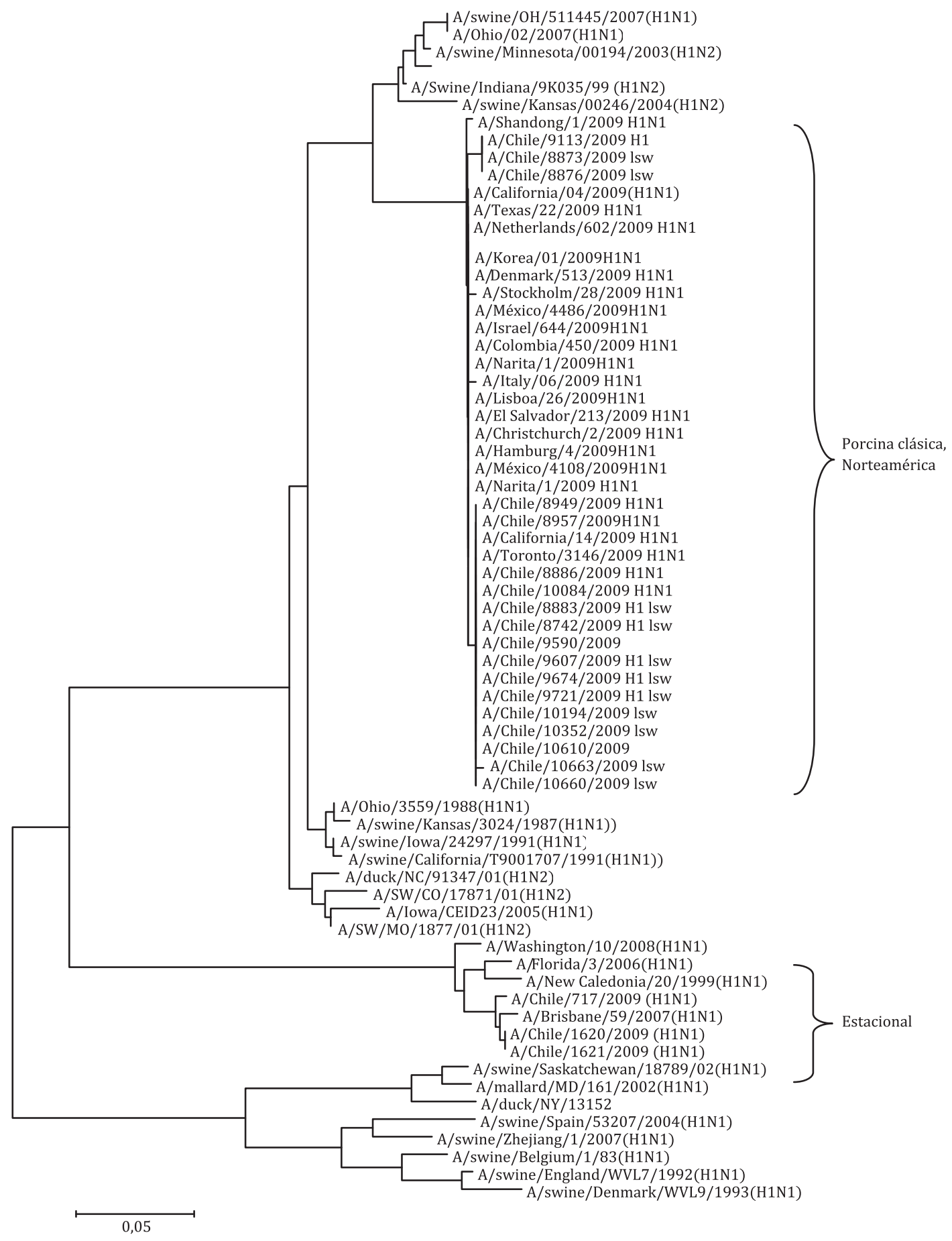

Figura 1. Análisis filogenético del gen de la Hemaglutinina (HA) de 18 pacientes chilenos con el virus de la Influenza A (H1N1) pandémica de 2009. 
2 se infectaron en República Dominicana y el tercer caso se infectó durante el vuelo a Chile. A su vez podemos afirmar que ambos grupos fueron infectados desde diferentes fuentes epidemiológicas. El caso 4 fue un niño que comenzó con los síntomas el 11 de mayo, es decir, cinco días antes de la llegada a Chile de los dos casos confirmados provenientes de República Dominicana. Este niño residente en Santiago no tuvo contacto con personas provenientes de extranjero. Estos resultados demuestran que el virus estaba circulando en Santiago antes del 11 de mayo. La variante viral detectada en este grupo, estaba ampliamente distribuida en México, Estados Unidos de Norteamérica y países de Europa. Sin embargo, no fue posible determinar con certeza la fecha del inicio de la circulación del virus en Chile.

El análisis genético del virus Influenza obtenido de casos de diferentes ciudades de Chile, separadas por alrededor del $3.000 \mathrm{~km}$, tales como Arica (Caso 16) y Puerto Montt (Caso 15), demostró que las secuencias nucleotídicas de la Hemaglutinina tenían distintas substituciones aminoacídicas con respecto a la cepa de referencia. Sin embargo, ninguna de estas secuencias tenía las mutaciones encontradas en los virus Influenza de los pacientes de República Dominicana y Panamá. Estos resultados demuestran que los casos estudiados en 7 ciudades diferentes del país, cuyos pacientes no informaron viajes al extranjero durante el mes de mayo, fueron infectados con el virus pandémico que estaba circulando en Chile desde finales del mes de abril. Por otra parte, en un estudio retrospectivo realizado en la región de los Lagos se indica que probablemente el brote se inició alrededor del 28 de abril en esa región ${ }^{13}$. El primer caso confirmado de esa región correspondió a una persona de Puerto Montt el 19 de mayo de 2009. Por lo tanto, es probable que el virus pandémico estaba presente en nuestro país desde el mes de abril, siendo introducido por personas asintomáticas al momento de su llegada al país. Es importante mencionar que el Ministerio de Salud emitió una alerta epidemiológica a todos los sistemas de Salud el 24 de abril y que más de 100 muestras fueron analizadas por el Instituto de Salud Pública de Chile antes de los casos provenientes de República Dominicana. Durante esas 3 semanas sólo fueron detectados por RT-PCR dos virus estacionales $\mathrm{H} 1 \mathrm{~N} 1$ provenientes de Santiago y un caso de Influenza A(H3N2) de Puerto Montt.

En conclusión, nuestros resultados demuestran que el comienzo del brote de Influenza pandémica en Chile podría haber sido originado en al menos dos diferentes grupos epidemiológicos. El virus encontrado en los tres pasajeros provenientes de República Dominicana y Panamá fue inmediatamente limitado, ya que no se extendió mucho más allá de estos tres casos. En cambio, el virus detectado en el caso 4 que fue el primer caso confirmado en Chile sin historial de viaje, se encontró en diferentes regiones del país. Estos hallazgos, permiten sugerir que los primeros casos en Chile podrían haber aparecido a fines del mes de abril.

Agradecimientos. Agradecemos al personal del Subdepartamento de Enfermedades Virales y de Genética Molecular del ISP, por su gran esfuerzo y soporte técnico. De igual manera se agradece al personal de los laboratorios de la red pública, y privada que enviaron muestras para su confirmación al laboratorio de Referencia del Instituto de Salud Pública de Chile

\section{Referencias}

1. Vincent AL, Ma W, Lager KM, Janke BH, Richt JA. Swine influenza viruses: A North American perspective. Adv Virus Res 2008; 72: 127-54.

2. Shinde V, Bridges CB, Uyeki TM, Shu B, Balish A, Xu $\mathrm{X}$, et al. Triple-reassortant swine influenza A (H1) in humans in the United States, 2005-2009. N Engl J Med 2009; 360: 2616-25.

23. Domínguez-Cherit G, Lapinsky S, Macias A, Pinto R, Espinosa-Pérez L, de la Torre A., et al. Critically ill patients with 2009 Influenza $\mathrm{A}(\mathrm{H} 1 \mathrm{~N} 1)$ in Mexico. JAMA 2009; 302: 1880-7.

4. Centers for Disease Control and Prevention (CDC) Swine influenza A (H1N1) infection in two childrenSouthern California, March-April 2009. MMWR Morb Mortal Wkly Rep 2009;5 8 (15): 400-2.

5. Organización Mundial de la Salud (OMS). El nivel de alerta de pandemia de gripe se eleva de la fase 5 a la fase http://www.who.int/mediacentre/news/statements /2009 /h1n1_pandemic_phase6_20090611/es/index.

6. Canals M. Análisis comparado de la dinámica epidemiológica de la influenza A(H1N1) en Chile. Rev Med Chile 2010; 138: 1186-96.

7. World Health Organization. 2009. Influenza A(H1N1)update 81. http://www.who. int/csr/don/2009_12_30/en/ index.html (Accesed December 30, 2009).

8. Ministerio de Salud de Chile. Vigilancia de influenza 
2009. http://www.redsalud.gov. cl/portal/url/item/74e5 81e26ec299e2e04001011f017805.

9. Centers for Disease Control and Prevention (CDC). 2009. H1N1 Influenza Virus Biosafety Guidelines for Laboratory Workrs. http://cdc.gov/h1n1flu/guidelines workers.

10. World Health Organization. CDC protocol of realtime RTPCR for influenza A (H1N1)2009.http://www.who. int/csr/resources/publications/swineflu/realtimeptpcr/ en/index.

11. Centers for Disease Control and Prevention (CDC).
Sequencing primers and protocol 2009..http://www. who.int/csr/resources/publications/swineflu/GenomePrimers_200905.

12. Kumar S, Tamura K, Nei M. MEGA3: integrated software for molecular evolutionary genetics analysis and sequence alignment. Breif Bioinform 2004; 5: 150-63.

13. Pedroni E, García M, Espínola V, Guerrero A, González C, et al. Outbreak of 2009 pandemic influenza A(H1N1), Los Lagos, Chile, April-June 2009. Surveillance and outbreak reports 2009. http://www.eurosurveillance.org/ images/dynamic/EE/V15 N01/art19456.pdfos. 